\title{
Variation in Trauma Admission During the COVID-19 Pandemic in a Major Trauma Unit - An Observational Study
}

\author{
Alasdair JA Santini ${ }^{* 1,2}$, Andy Molloy ${ }^{1,2}$, Joanna Craven ${ }^{1}$, John D Moorehead ${ }^{1}$, Adam Truss ${ }^{1}$, Katy \\ Clay $^{1}$, Paula Houghton ${ }^{1}$ and Lyndon Mason ${ }^{1,3}$ \\ ${ }^{1}$ Liverpool University Hospitals NHS Foundation Trust, Liverpool, UK \\ ${ }^{2}$ Faculty of Health and Life Science, The University of Liverpool, UK
}

${ }^{3}$ School of Medicine, The University of Liverpool, UK

ORCID: Alasdair Santini 0000-0003-2281-2133

ORCID: Lyndon Mason 0000-0002-0371-3183

ORCID: Andy Molloy 0000-0001-7410-5372

ORCID: John Moorehead 0000-0001-7535-9518

*Corresponding author: Alasdair Santini, Liverpool University Hospitals NHS Foundation Trust, Faculty of Health and Life Science,

The University of Liverpool, Liverpool, UK

ARTICLE INFO
Received: 幽 March 17, 2021
Published: 慧 March 30, 2021

Citation: Alasdair JA Santini, Andy Molloy, Joanna Craven, John D Moorehead, Adam Truss, et al., Variation in Trauma Admission During the COVID-19 Pandemic in a Major Trauma Unit - An Observational Study. Biomed J Sci \& Tech Res 34(5)-2021. BJSTR. MS.ID.005615.

Keywords: COVID-19; Trauma; Hip; Lockdown; Rationing; Outcome

Abbreviations: SARS-CoV-2: Severe Acute Respiratory Syndrome Coronavirus 2; BOA: British Orthopaedic Association; LOTS: Liverpool Orthopaedic and Trauma Service; VFC: Virtual Fracture Clinic
ABSTRACT

Purpose: Following the World Health Organization declaration of a COVID-19 pandemic, there was a severe impact on UK trauma provision. Our aim in this paper was to examine the effect of alteration in working patterns and 'lockdown' on trauma and orthopaedic referral and management in a major trauma centre.

Methods: All trauma referrals to the Liverpool Orthopaedic and Trauma Service were analysed over a 33-week period, divided into 'Pre-lockdown', 'Lockdown', and 'Postlockdown'.

Results: 1661 orthopaedic trauma operations were undertaken - 967 in 'prelockdown', 193 in 'lockdown' and 501 in 'post-lockdown'. An average weekly reduction in numbers of referrals to virtual fracture clinic and trauma cases undergoing surgery was observed, with numbers in virtual fracture clinic and in trauma cases undergoing surgery falling by similar amounts from prelockdown to lockdown $51.71 \%$ drop in virtual fracture clinic referrals and $54.38 \%$ reduction in trauma cases undergoing surgery). Hip fractures occupied significantly more theatre time compared to other trauma in the lockdown period. Post-lockdown, there was a rebound effect in the trauma numbers of lower limb surgery (excluding hip) and central surgery.

Conclusion: The COVID-19 pandemic lockdown resulted in a significant change in practice and a reduction in both the presenting trauma numbers and those undergoing surgery in our trauma and orthopaedic department. The effect of the lockdown on trauma numbers has had a major mitigating effect on the consequences of rationing of resources.

\section{Introduction}

On $11^{\text {th }}$ March 2020, the World Health Organization declared a COVID-19 pandemic with the Severe Acute Respiratory Syndrome Coronavirus 2 (SARS-CoV-2) [1]. The official UK lockdown commenced on 23rd March 2020, with government enforced guidelines stopping all elective surgical practice and limiting the options for trauma surgery [2]. Changes included orthopaedic surgeons running Minor Injury departments; redistribution of junior surgeons to medical wards; and limitations on face-to-face consultations [3]. With the risk of COVID-19 infection to both 
patients and medical personnel being largely unknown, nonemergency services were reduced [4]. Guidelines were issued by groups including The British Orthopaedic Association (BOA) and the Federation of Surgical Specialty Associations advising how to apportion services with priorities set to maintain emergency surgery provision; protecting the surgical workforce; fulfilling alternative surgical and non-surgical roles; and how to rank cases according to importance [5-7]. This created ethical dilemmas, that reasonable decisions were to be made based on best evidence available at the time and in a collaborative way as much possible [8]. The Liverpool University Hospitals NHS Foundation Trust contains the region's major trauma centre, serving a population of 2.5 million, where the Liverpool Orthopaedic and Trauma Service (LOTS) resides. Due to the COVID-19 pandemic, LOTS produced local policies that supported triaging of urgent procedures and the implementing of alternative management based on the BOAST guidelines [5,7]. This included the non-surgical treatment of cases where possible, and preservation of surgical resources where significant morbidity or mortality was predicted if surgery was not performed. Our aim in this paper was to examine the effect of alteration in working patterns in 'lockdown' on orthopaedic trauma referral and management in a major trauma centre.

\section{Methods}

This study was a retrospective, observational study of prospectively collected data by LOTS. The study was conducted under the auspices of a service evaluation, therefore no ethical approval was required. All trauma patients referred to LOTS have their data prospectively collected and added to our database (Bluespier, Droitwich, UK). This includes inpatient and outpatient trauma referrals, with all accident and emergency attendances either referred directly to the on-call team or via the Virtual Fracture Clinic (VFC), where all acute ambulatory trauma is triaged by a consultant trauma surgeon and specialist physiotherapist The data collected includes standard demographic data, trauma categorisation, surgical intervention, post-operative outcomes and complications. A 33-week period was retrospectively analysed with inclusion criteria being all trauma referred to LOTS between the $2^{\text {nd }}$ December 2019 and $16^{\text {th }}$ July 2020. Trauma cases were characterised by AO/OTA classification and anatomical subspecialties of upper limb, central surgery (pelvis and rib), hip fractures (including all proximal femur fractures), and lower extremity surgery excluding hip fractures [9]. Our unit does not perform spinal surgery with all relevant cases transferred to the regional spinal unit, and were therefore not included. Where more than one anatomical site required surgical intervention, this was included as more than one procedure. Major trauma related information was identified via the prospectively collected database submitted to the Trauma Audit and Research Network and the National Hip Fracture database was also analysed to ensure all data was complete $[10,11]$. Initially,
SARS-CoV-2 testing was not undertaken unless patients were symptomatic with routine testing introduced on $1^{\text {st }}$ June. Three time intervals were defined, totalling 33-weeks; 'Pre-lockdown' covering 16 weeks before $23^{\text {rd }}$ March; 'Lockdown' covering nine weeks from $23^{\text {rd }}$ March to $24^{\text {th }}$ May; and 'Post-lockdown' covering eight weeks from $24^{\text {th }}$ May to $16^{\text {th }}$ July as in previous studies [12]. Time periods were dictated by the UK Government announcements of national lockdown and easing of lockdown measurements [13]. The 16 week 'pre-lockdown' period was defined from when the merger of the hospitals occurred; prior to then, the hospitals acted separately but not equally and hence comparison could not be made. COVID-19 infection was confirmed by laboratory testing based on SARS-Cov-2 viral RNA detection by quantitative RT-PCR. Due to the limited testing availability in the early part of the COVID-19 outbreak, patients were also included based on either clinical or radiological findings. Cumulative COVID-19 infection rate for the hospital was calculated as the cumulative number of positive COVID-19 cases from $11^{\text {th }}$ March 2020 when the global pandemic was announced. This was expressed as a percentage of the total number of cases performed from the date.

\section{Statistical Analysis}

The study was completed according to STROBE guidelines for observational studies [14]. Continuous variables were tested for normality distribution and presented as means with $95 \%$ confidence intervals. Categorical and qualitative variables are expressed as numbers and percentages. The Student t-test was used for continuous variables if the criteria for normality and equality of variances were fulfilled. Alternatively, the Mann-Whitney U test was performed. Categorical variables were analysed using the Chisquare test for sample sets greater than 5, otherwise the Fisher's exact test was used. The one-way analysis of variance (ANOVA) was used where comparison between the means of three or more independent groups was required. A p value less than 0.05 was considered significant. All data were assessed using SPSS Version 26.0 (SPSS Inc., IBM, Chicago, IL).

\section{Results}

\section{Overall Orthopaedic Trauma Surgical Procedures}

In the 33-week analysis period, 1661 orthopaedic trauma operations were undertaken with 967 procedures in pre-lockdown, 193 procedures in lockdown and 501 cases in the post-lockdown periods. The number of cases performed per week showed a significant difference across the time periods $(\mathrm{p}<.001)$ with much higher volumes being performed pre-lockdown as compared to lockdown and post-lockdown periods (Table 1).

\section{Surgical Procedures by Anatomical Location}

In the entire cohort there were 337 upper extremity procedures, 54 central surgeries, 552 hip fracture procedures, 
532 lower extremity procedures and 186 'otherwise' classified. There were significant decreases in the average cases per week for all anatomical locations between pre-lockdown and lockdown (Table $1 \&$ Figure 1). Comparing average percentage of procedures undertaken per week, hip fractures occupied significantly more theatre space during lockdown due to priority given to them with non-operative treatment being potentially more appropriate for other anatomical locations (Table 1 \& Figure 2). Post-lockdown, there was a rebound effect in both central surgery and lower extremity surgery (excluding hip fractures) in both numbers and percentage of theatre time allocation. During the 33-weeks, we treated a mean of 16.72 hip fractures per week with the weekly average higher pre-lockdown (18.50 per week) than during lockdown (12.43 per week) and post-lockdown (16.90 per week) (Table 1).

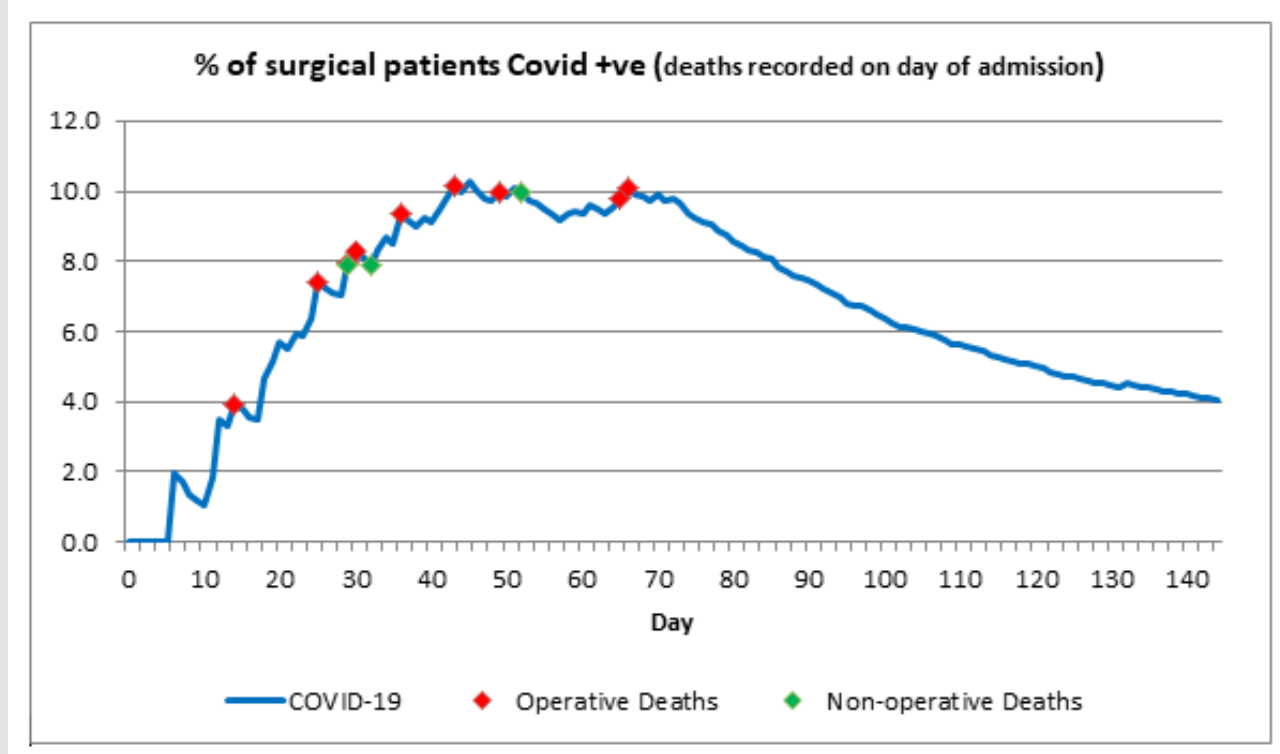

Figure 1: Graphical representation of numbers of cases per week by anatomical location. Vertical lines represent division of time periods.

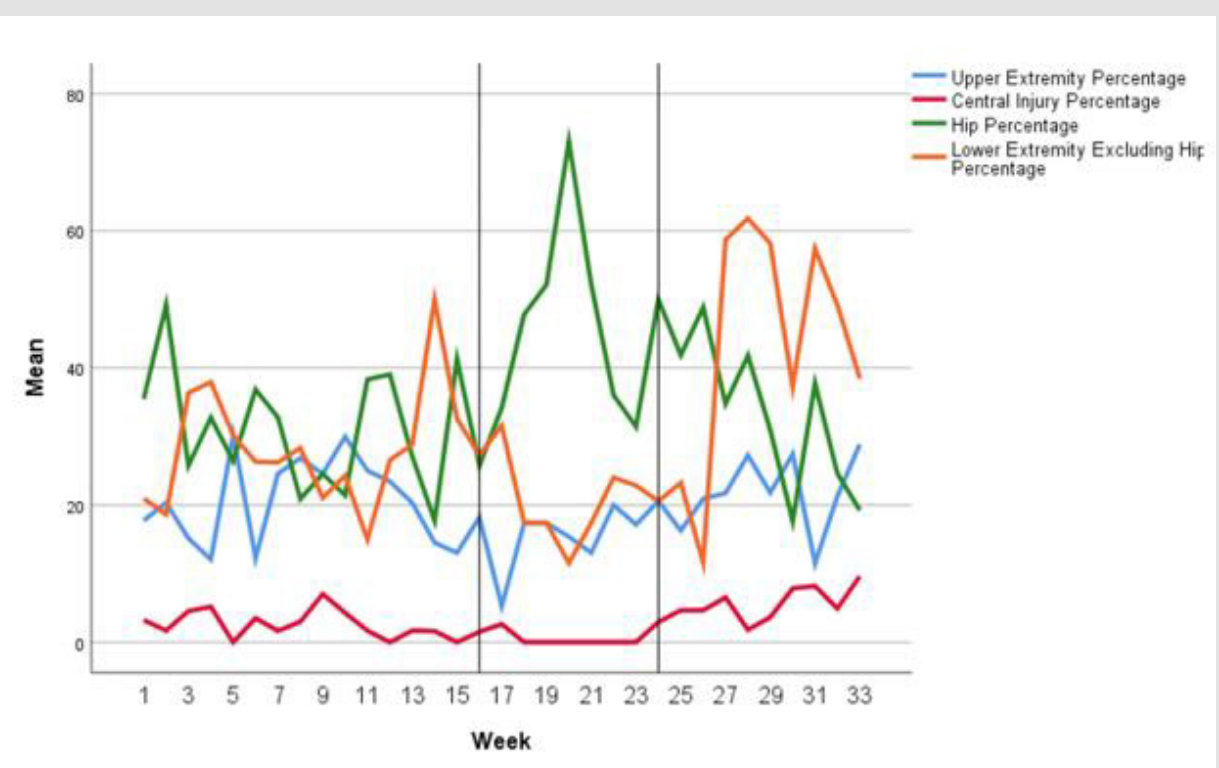

Figure 2: Graphical representation of percentage of cases per week by anatomical location. Vertical lines represent division of time periods. 
Table 1: Surgical procedure categorisation with weekly average numbers of procedures and weekly percentage of total cases per anatomical location.

\begin{tabular}{|c|c|c|c|c|c|c|c|c|c|}
\hline & & \multirow{2}{*}{$\begin{array}{l}\text { Number } \\
\text { (mean) }\end{array}$} & \multicolumn{2}{|c|}{$\begin{array}{l}\text { 95\% Confidence } \\
\text { Interval }\end{array}$} & \multirow[t]{2}{*}{$P$ Value } & \multirow{2}{*}{$\begin{array}{l}\text { Percentage } \\
\text { of Total } \\
\text { (mean) }\end{array}$} & \multicolumn{2}{|c|}{$\begin{array}{l}\text { 95\% Confidence } \\
\text { Interval }\end{array}$} & \multirow[t]{2}{*}{ P Value } \\
\hline & & & Lower & Upper & & & Lower & Upper & \\
\hline \multirow{3}{*}{ Total } & Pre-Lockdown & 60.44 & 57.32 & 63.55 & \multirow{3}{*}{0} & & & & \\
\hline & Lockdown & 27.57 & 21.77 & 33.37 & & & & & \\
\hline & Post-Lockdown & 50.1 & 43.94 & 56.26 & & & & & \\
\hline \multirow{3}{*}{ Upper Extremity } & Pre-Lockdown & 12.5 & 10.28 & 14.72 & \multirow{3}{*}{0} & 20.52 & 17.27 & 23.77 & \multirow{3}{*}{0.055} \\
\hline & Lockdown & 4 & 2.91 & 5.19 & & 15.09 & 10.62 & 19.55 & \\
\hline & Post-Lockdown & 10.9 & 8.53 & 13.27 & & 21.77 & 17.99 & 25.55 & \\
\hline \multirow{3}{*}{ Central Surgery } & Pre-Lockdown & 1.68 & 0.92 & 2.21 & \multirow{3}{*}{0} & 2.54 & 1.47 & 3.6 & \multirow{3}{*}{0} \\
\hline & Lockdown & 0.14 & -0.21 & 0.49 & & 0.38 & -0.54 & 1.3 & \\
\hline & Post-Lockdown & 2.8 & 1.74 & 3.86 & & 5.48 & 3.69 & 7.27 & \\
\hline \multirow{3}{*}{$\begin{array}{l}\text { Lower Limb } \\
\text { Excluding Hip }\end{array}$} & Pre-Lockdown & 17 & 14.16 & 19.84 & \multirow{3}{*}{0.001} & 28.16 & 23.69 & 32.63 & \multirow{3}{*}{0.003} \\
\hline & Lockdown & 5.86 & 2.91 & 8.8 & & 20.31 & 14.34 & 26.27 & \\
\hline & Post-Lockdown & 21.9 & 13.73 & 30.07 & & 41.64 & 28.61 & 54.68 & \\
\hline \multirow{3}{*}{ Hip Fracture } & Pre-Lockdown & 18.5 & 15.99 & 21.01 & \multirow{3}{*}{0.02} & 30.96 & 26.36 & 35.56 & \multirow{3}{*}{0.012} \\
\hline & Lockdown & 12.43 & 9.51 & 15.35 & & 46.7 & 33.29 & 60.1 & \\
\hline & Post-Lockdown & 16.9 & 13.47 & 20.33 & & 34.74 & 26.51 & 42.97 & \\
\hline
\end{tabular}

\section{COVID-19 Infection}

Thirty-six surgically treated patients were diagnosed with COVID-19 accounting for $2.17 \%$ of all patients. The daily percentage varied, reaching a cumulative high of $10.29 \%$ on $29^{\text {th }}$ April 2020, day 49, when 243 had undergone surgical procedures and 25 cases were confirmed COVID-19 positive (Figure 3). Of the COVID-19 positive patients, 31 (88.6\%) suffered a hip fracture with the others having peri-prosthetic fractures $(n=2)$; a hand wound $(n=1)$; an open tibial fracture $(n=1)$; and a dislocated total hip arthroplasty $(n=1)$. Eight of the COVID-19 positive surgically treated patients subsequently died equating to $0.48 \%$ of all operated patients, with the mortality rate of COVID-19 positive patients being $22.22 \%$. We do not have the data available to assess the incidence of COVID-19 in all the patients referred to the department including the outpatients.

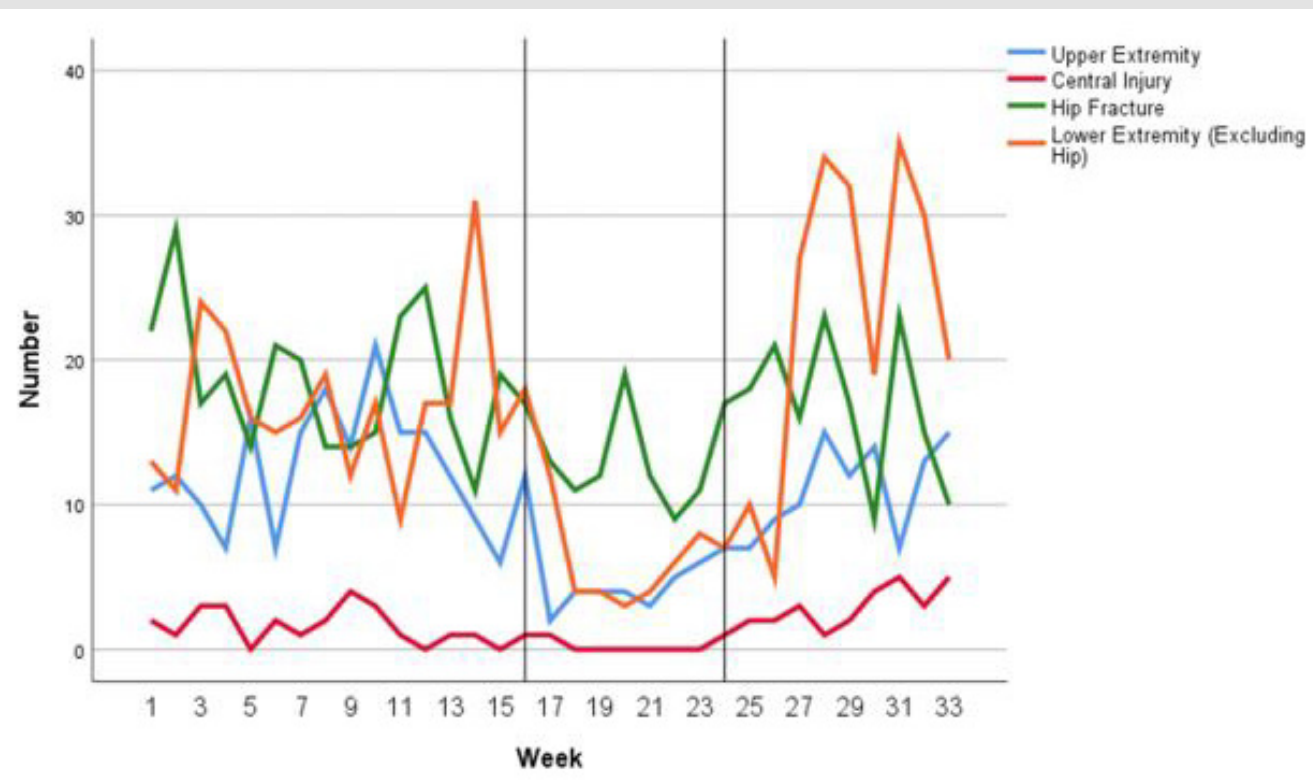

Figure 3: Percentage cases of COVID-19 infection in orthopaedic trauma from announcement of pandemic by WHO on the $11^{\text {th }}$ March 2020 (day 1). The curve shows on each day what percentage of the total admissions had COVID-19. Individual deaths are indicated by diamonds. All deaths occurred within $1^{\text {st }} 30$ days. 


\section{COVID-19 Testing}

Of the COVID-19 confirmed patients, two had changes on their admitted chest radiograph suggestive of COVID-19 and both were subsequently positive. Four had clinical signs suggestive of COVID-19 infection on admission, but the remaining 30 patients had no indication of infection. Fourteen patients had one negative swab prior to testing positive, and four patients had two negative swabs. The average time for a patient to test positive was on day ten after admission. The eight surgically treated patients who died, tested positive on average on day six. No patient had an alteration in their treatment as a result of their swab result.

\section{Virtual Fracture Clinic}

The mean total number of VFC referrals per week reduced significantly once lockdown started (221.13 vs 109.00) and remained lower in the post-lockdown period (203.13 p/w) (Table 2). Regardless of the overall reduction in numbers, the percentage VFC outcomes remained relatively unchanged with the percentage referred to fracture clinic, discharged, unable to contact and referred to physiotherapy being the same throughout the periods analysed (Table 2). However, there was a significant reductions in patients sent to elective or extended scope practitioner clinics, which is most likely due to the reduction in resources that were available due to re-allocation or shielding of staff (Table 3).

Table 2: Virtual Fracture Clinic categorisation of result of clinic appointment as both average number per week and percentage of total cases per week.

\begin{tabular}{|c|c|c|c|c|c|c|c|c|c|}
\hline & & \multirow[t]{2}{*}{ Mean } & \multicolumn{2}{|c|}{ 95\% Confidence Intervals } & \multirow[t]{2}{*}{$\mathrm{p}$ Value } & \multirow[t]{2}{*}{ Mean } & \multicolumn{2}{|c|}{$\begin{array}{l}\text { 95\% Confidence } \\
\text { Intervals }\end{array}$} & \multirow[t]{2}{*}{$\mathrm{p}$ Value } \\
\hline & & & Lower & Upper & & & Lower & Upper & \\
\hline \multirow{3}{*}{ Total referrals } & Pre Lockdown & 221.13 & 203.68 & 238.57 & \multirow{3}{*}{0} & & & & \\
\hline & Lockdown & 109 & 89.56 & 128.44 & & & & & \\
\hline & Post-Lockdown & 203.13 & 193.44 & 212.81 & & & & & \\
\hline \multirow{3}{*}{ Fracture Clinic } & Pre Lockdown & 130.19 & 117.1 & 143.27 & \multirow{3}{*}{0} & $63.38 \%$ & $58.21 \%$ & $68.54 \%$ & \multirow{3}{*}{0.183} \\
\hline & Lockdown & 64 & 48.8 & 79.2 & & $57.02 \%$ & $50.95 \%$ & $63.10 \%$ & \\
\hline & Post-Lockdown & 128 & 115.66 & 140.34 & & $63.28 \%$ & $58.07 \%$ & $68.49 \%$ & \\
\hline \multirow{3}{*}{ Discharged } & Pre Lockdown & 42.81 & 40.03 & 45.6 & \multirow{3}{*}{0} & $20.91 \%$ & $19.72 \%$ & $22.10 \%$ & \multirow{3}{*}{0.097} \\
\hline & Lockdown & 25.56 & 22.36 & 28.75 & & $23.81 \%$ & $19.98 \%$ & $27.63 \%$ & \\
\hline & Post-Lockdown & 47.25 & 40.92 & 53.58 & & $23.38 \%$ & $20.41 \%$ & $26.35 \%$ & \\
\hline \multirow{3}{*}{ Unable to contact } & Pre Lockdown & 16.69 & 13.33 & 20.04 & \multirow{3}{*}{0.081} & $8.02 \%$ & $6.63 \%$ & $9.41 \%$ & \multirow{3}{*}{0.152} \\
\hline & Lockdown & 11.33 & 8.81 & 13.85 & & $10.29 \%$ & $8.41 \%$ & $12.17 \%$ & \\
\hline & Post-Lockdown & 16.5 & 10.81 & 22.19 & & $8.23 \%$ & $5.25 \%$ & $11.21 \%$ & \\
\hline \multirow{3}{*}{ Elective referral } & Pre Lockdown & 3.13 & 2.15 & 4.1 & \multirow{3}{*}{0} & $1.53 \%$ & $1.04 \%$ & $2.02 \%$ & \multirow{3}{*}{0.001} \\
\hline & Lockdown & 0.89 & 0.08 & 1.7 & & $0.80 \%$ & $0.10 \%$ & $1.49 \%$ & \\
\hline & Post-Lockdown & 0.25 & -0.34 & 0.84 & & $0.12 \%$ & $-0.17 \%$ & $0.41 \%$ & \\
\hline \multirow{3}{*}{ Referred to PT/OT } & Pre Lockdown & 13.81 & 10.85 & 16.78 & \multirow{3}{*}{0.003} & $6.61 \%$ & $5.36 \%$ & $7.87 \%$ & \multirow{3}{*}{0.62} \\
\hline & Lockdown & 6.67 & 3.98 & 9.36 & & $6.21 \%$ & $3.73 \%$ & $8.70 \%$ & \\
\hline & Post-Lockdown & 11.13 & 8.32 & 13.93 & & $5.55 \%$ & $4.07 \%$ & $7.02 \%$ & \\
\hline \multirow{3}{*}{$\begin{array}{l}\text { Extended scope } \\
\text { practitioner clinic }\end{array}$} & Pre Lockdown & 14.44 & 8.89 & 19.99 & \multirow{3}{*}{0} & $6.89 \%$ & $4.23 \%$ & $9.56 \%$ & \multirow{3}{*}{0} \\
\hline & Lockdown & 0.44 & -0.33 & 1.22 & & $0.33 \%$ & $-0.27 \%$ & $0.93 \%$ & \\
\hline & Post-Lockdown & 0 & 0 & 0 & & $0.00 \%$ & $0.00 \%$ & $0.00 \%$ & \\
\hline \multirow{3}{*}{ MCAS } & Pre Lockdown & 0.06 & -0.07 & 0.2 & \multirow{3}{*}{0.654} & $0.09 \%$ & $-0.11 \%$ & $0.28 \%$ & \multirow{3}{*}{0.499} \\
\hline & Lockdown & 0.11 & -0.15 & 0.37 & & $0.03 \%$ & $-0.03 \%$ & $0.09 \%$ & \\
\hline & Post-Lockdown & 0 & 0 & 0 & & $0.00 \%$ & $0.00 \%$ & $0.00 \%$ & \\
\hline
\end{tabular}

Table 3: Orthopaedic trauma diagnosis of COVID-19 positive patients.

\begin{tabular}{|c|c|c|c|c|}
\hline Diagnosis & $\begin{array}{c}\text { Number of +ve } \\
\text { COVID-19 cases }\end{array}$ & $\begin{array}{c}\text { \% of all COVID-19 } \\
\text { +ve }\end{array}$ & $\begin{array}{c}\text { Number of CovID-19 } \\
\text { related deaths }\end{array}$ & \begin{tabular}{c} 
\% of deaths \\
\hline Intracapsular NOF Fracture
\end{tabular} \\
\hline Intertrochanteric NOF Fracture & 15 & 42.86 & 4 & 33.33 \\
\hline Subtrochanteric NOF Fracture & 4 & 34.29 & & 66.66 \\
\hline Peri-prosthetic fracture of TKR & 1 & 11.43 & & \\
\hline
\end{tabular}




\begin{tabular}{|c|c|c|c|c|}
\hline Dislocated THR & 1 & 2.86 & & \\
\hline Hand wound & 1 & 2.86 & & \\
\hline Open Tibia Fracture & 1 & 2.86 & & \\
\hline Total & 35 & & 6 & \\
\hline
\end{tabular}

\section{Discussion}

The aim of our study was to examine the effect of alteration in working patterns and 'lockdown' on trauma and orthopaedic referral and management in a major trauma centre. Our study has clearly shown that major differences occurred. Lockdown in the UK had the effect of dramatically reducing the trauma cases presenting to our region. When the UK Government announced a national 'lockdown' and social distancing guidance, people stayed home; sporting events were cancelled or severely curtailed; and hospitality venues were closed [13]. We changed the way we lived our lives, undertook hobbies, how far we travelled and what mode of transport we used and this likely affected hospital trauma attendances. Prioritisation of trauma cases in our unit occurred due to the reallocation of resources. The trauma list provision was reduced from four to one daily trauma lists with doctors allocated to other duties. These mirrored the recommendations given by various surgical bodies both in the UK and Europe such as the BOA and the European Trauma Society $[5,15]$. Studies in the UK and in Germany also found similar reduction in both case load and resources to our findings $[16,17]$. In our unit, the emphasis was on a more consultant-led, non-surgical treatment of cases where possible. We have not analysed as part of this study the effect on the change of management on the clinical outcome of the affected patients. However, in a recent paper from our unit on foot and ankle surgery during the COVID-19 pandemic, it was shown that in 12 cases management was changed due to the COVID-19 pandemic resulting in three undergoing surgery at a later date [12]. There has been concern regarding the long term effect such rationing of care will have on patients who have had trauma, however it is clear in our study that the numbers of trauma referrals reduced proportionally to the number of undertaken surgical cases.

Comparing the average weekly reduction in case numbers in VFC showed that the referral of cases in VFC fell by $51.71 \%$ from pre-lockdown to lockdown, compared to the $54.38 \%$ reduction in surgical cases from pre-lockdown to lockdown. This illustrates that the main factor for our reduction in surgical cases was not the rationing of services but the general trend of trauma case referral. Taking into account the drop in referral of trauma cases, the decision making in VFC altered very little with no difference in patients discharged from clinic or numbers sent to face to face fracture clinic appointments. The only VFC difference was seen in the patients sent to elective of extended scope practitioner clinics, due to the loss of elective practice during lockdown and the reallocation of personnel from extended scope practitioner to other duties. Factors that may have led to the reduction in trauma case numbers, include changes in social mobility, family members being present at home with elderly relatives, the psychology of not wanting to attend hospital and the reduction in surgical treatment of fractures. It is most likely that all these factors contribute and further in-depth studies would be of interest. As published by Luengo-Alonso et al on the re-organisation of a Spanish hospital, the reduction in clinical numbers have been ubiquitous [18]. They reported that scheduled clinical appointments decreased by $22 \%$, urgent consultations decreased by $37 \%$ and discharge from clinics decreased by $20 \%$. Over $90 \%$ of all consultations became virtual with all elective surgery cancelled.

Hip and proximal femoral fractures make up a significant proportion of any trauma service. In our cohort, geriatric patients with hip fractures made up the majority of COVID-19 infected patients most likely due to the necessity for admission and operation. Our overall mortality rate for COVID-19 positive patients was $22.22 \%$ (8 deaths from 36 positive patients). For hip fracture patients specifically, who were COVID-19 positive, this increased to 29.63\% (8 deaths from 27 positive patients with hip fractures). The percentage of deaths were higher in intertrochanteric NOF fractures as compared to intercapsular NOF fractures $(41.66 \%$ versus $20.00 \%$ ). These results were similar to other COVID-19 hip fracture studies. Kayani's multi-centre review compared 340 COVID-19 negative patients with 82 COVID-19 positive patients undergoing surgery for hip fractures with a 30-day mortality rate of 30.5\% [19]. The COVIDSurg collaborative reported a 30-day mortality of $23.8 \%$ in 1,128 patients undergoing surgery of any kind [20]. Although there was a statistically significant difference in number of patients between time periods for hip fractures, the numbers did not alter to the levels of other anatomic locations. As indicated in Table 1 \& Figures 1 \& 2, that although hip fractures numbers reduced overall, the percentage of resource allocation to hip fracture surgery increased significantly. This is due to their prioritisation over other injuries and high numbers during lockdown as compared to other anatomical locations. Similarly, a study by Nuñez et al. reported on 6,565 patients in four different periods in a Spanish National Health System tertiary hospital concluding that contingency plans need to be carefully targeted as hip fractures did not decrease [21].

As aforementioned, our study has shown there were significant reductions in case numbers in all anatomical sites, with the largest reduction in surgical time resource allocation being seen in lower extremity fractures excluding hip. Hernigou et al. also showed a significant reduction in number of trauma admissions when they reviewed 140 orthopaedic admissions (commencing the $1^{\text {st }}$ March 
2020) when Belgium entered lockdown [22]. When compared to a control group from the same time period in 2018, they reported a $32 \%$ decrease in trauma patients. In our study, we were unable to use data from previous years for comparison, due to the significant alteration in our hospital systems due to a merger of two large trauma and orthopaedic units in 2019. Upper limb surgery numbers reduced on average by $68.00 \%$, however the surgical resource percentage didn't change. Similar reductions were published by Pichard et al in upper limb surgery, who reported a $64.9 \%$ decrease in the rate of upper limb emergencies [23]. Postlockdown the number of orthopaedic referrals to the department returned to similar levels as the pre-lockdown periods. However, there was a significant increase in surgical resource allocation to lower limb surgery (excluding hip fractures) and central surgery post-lockdown as compared to pre-lockdown. There are a number of factors that could contribute to this. These include an alteration in case mix due to changes in population activity, seasonal effects, and previously conservatively managed cases now requiring surgery. Further work looking at the outcomes of patients who have had they management changed as a consequence to the COVID-19 pandemic may illustrate these changes in practice further.

Our study has limitations. This was a retrospective study of observational data. This study included all patients undergoing orthopaedic trauma surgery in an operating theatre, however during the lockdown period a number of patients may have had interventions outside of an operating theatre. As we did not assess the management decisions in this paper, we may not have included patients who had sedation in the emergency department or fracture clinic. Similarly, we have not analysed the complexity of cases seen in our department, and all inferences have been made on total numbers of cases which can create bias. As a retrospective series, some datasets were incomplete and there is a higher chance of errors in dates recorded.

\section{Conclusion}

The COVID-19 pandemic lockdown resulted in a significant change in practice and a reduction in both the presenting trauma numbers and those undergoing surgery in our orthopaedic department. The effect of the lockdown on reducing trauma numbers has mitigated the consequences of rationing of resources

\section{Conflicts of Interest}

The authors have no conflicts of interest.

\section{Funding}

No funding

\section{Ethics Approval}

Not required

\section{Consent to Participate}

Not applicable

\section{Consent for Publication}

Not applicable

\section{Availability of Data and Material}

Available if requested.

\section{Code Availability}

Not applicable.

\section{Authors Contributions}

All authors contributed to the study conception and design. Material preparation, data collection and analysis were performed by Alasdair Santini, Andy Molloy, Joanna Craven, John Moorehead, Adam Truss, Katy Clay, Paula Houghton and Lyndon Mason. The first draft of the manuscript was written by Alasdair Santini and Lyndon Mason and all authors commented on previous versions of the manuscript. All authors read and approved the final manuscript.

\section{References}

1. (2020) World Health Organization. WHO Director - General's Opening Remarks at the Media Briefing on COVID-19.

2. (2020) The Rt Hon Boris Johnson MP. Prime Minister's Statement on Coronavirus (COVID-19).

3. Kulkarni S (2020) The Bone Prone Team. J Clin Orthop Trauma 11(4): S446-S447.

4. Huang C, Wang Y, Li X, Lili Ren, Jianping Zhao, et al. (2020) Clinical Features of Patients Infected with 2019 Novel Coronovirus in Wuhan, China. Lancet 395: 497-506.

5. (2020) BOAST. Management of Patients with Urgent Orthopaedic Conditions and Trauma During the Coronavirus Pandemic. In British Orthopaedic Association.

6. (2020) Guidance for Surgeons Working During the COVID-19 Pandemic. In Royal College of Surgeons of England.

7. (2020) FSSA. Clinical Guide to Surgical Prioritisation During the Coronoavirus Pandemic. In: Federation of Surgical Speciality Associations, UK.

8. (2020) BMA. COVID-19 - ethical issues. A guidance note. In: The British Medical Association.

9. Meinberg EG, Agel J, Roberts CS, Karam MD, Kellam JF (2018) Fracture and Dislocation Classification Compendium 2018. J Orth Trauma 32(1): S1-S170.

10. (2020) TARN-The trauma Audit and Research Network.

11. (2020) NHFD. National Hip Fracture Database.

12. Stringer H, Molloy A, Craven J, Moorehead J, Santini AJA, et al. (2021) The impact of COVID-19 on foot and ankle surgery in a major trauma centre. Foot (Edinb) 46: 101772.

13. (2020) UK Government. Staying at home and away from others (social distancing).

14. (2014) Observational Studies: Getting Clear about Transparency. PLoS Medicine 11(8): e1001711. 
15. Coimbra R, Edwards S, Kurihara H, Gary Alan Bass, Zsolt J Balogh, et al. (2020) European Society of Trauma and Emergency Surgery (ESTES) recommendations for trauma and emergency surgery preparation during times of COVID-19 infection. Eur J Trauma Emerg Surg 46(3): 505-510.

16. Haffer H, Schomig F, Rickert M, Thomas Randau, Michael Raschke, et al. (2020) Impact of the COVID-19 Pandemic on Orthopaedic and Trauma Surgery in University Hospitals in Germany: Results of a Nationwide Survey. J Bone Joint Surg Am 102(14): e78.

17. Khan H, Williamson M, Trompeter A (2020) The impact of the COVID-19 pandemic on orthopaedic services and training in the UK. Eur J Orthop Surg Traumatol 26: 1-5.

18. Luengo Alonso G, Pérez Tabernero FG, Tovar Bazaga M, Arguello Cuenca JM, Calvo E (2020) Critical adjustments in a department of orthopaedics through the COVID-19 pandemic. Int Orthop 44(8): 1557-1564.

19. Kayani B, Onochie E, Patil V, Fahima Begum, Rory Cuthbert, et al. (2020) The effects of COVID-19 on perioperative morbidity and mortality in patients with hip fractures. Bone Joint J 102-B (9): 1136-1145.

\section{ISSN: 2574-1241}

DOI: 10.26717/BJSTR.2021.34.005615

Alasdair JA Santini. Biomed J Sci \& Tech Res

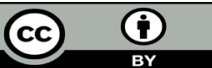

This work is licensed under Creative Commons Attribution 4.0 License

Submission Link: https://biomedres.us/submit-manuscript.php
20. (2020) COVID Surg Collaborative. Mortality and pulmonary complications in patients undergoing surgery with perioperative SARSCoV-2 infection: an international cohort study. Lancet 396(10243): $27-$ 38.

21. Nuñez JH, Sallent A, Lakhani K, Ernesto Guerra-Farfan, Nuria Vidal, et al. (2020) Impact of the COVID-19 Pandemic on an Emergency Traumatology Service: Experience at a Tertiary Trauma Centre in Spain. Injury 51(7): 1414-1418.

22. Hernigou J, Morel X, Callewier A, Bath O, Hernigou P (2020) Staying home during "COVID-19" decreased fractures, but trauma did not quarantine in one hundred and twelve adults and twenty eight children and the "tsunami of recommendations" could not lockdown twelve elective operations. Int Orthop 44(8): 1473-80.

23. Pichard R, Kopel L, Lejeune Q, Masmoudi R, Masmejean E (2020) Impact on the CoronaVIrus Disease 2019 Lockdown on Hand and Upper Limb Emergencies: Experience of a Referred University Trauma Hand Centre in Paris, France. Int Orthop 44(8): 1497-1501.

$\begin{array}{ll}\text { BIOMEDICAL } & \text { Assets of Publishing with us } \\ \text { RESEARCHES } & \text { - Global archiving of articles } \\ & \text { - Immediate, unrestricted online access } \\ & \text { - Rigorous Peer Review Process } \\ & \text { - Authors Retain Copyrights }\end{array}$

